\title{
Depression in older cat and dog owners: the Nord- Trøndelag Health Study (HUNT)-3
}

Ingela Enmarker, Ove Hellzén, Knut Ekker \& Anne-Grethe T. Berg

To cite this article: Ingela Enmarker, Ove Hellzén, Knut Ekker \& Anne-Grethe T. Berg (2015) Depression in older cat and dog owners: the Nord-Trøndelag Health Study (HUNT)-3, Aging \& Mental Health, 19:4, 347-352, DOI: 10.1080/13607863.2014.933310

To link to this article: https://doi.org/10.1080/13607863.2014.933310

曲 Published online: 03 Jul 2014.

Submit your article to this journal $\pi$

Џll Article views: 1088

Q View related articles ๘

View Crossmark data

4 Citing articles: 19 View citing articles 


\title{
Depression in older cat and dog owners: the Nord-Trøndelag Health Study (HUNT)-3
}

\author{
Ingela Enmarker ${ }^{\mathrm{a}, \mathrm{b} *}$, Ove Hellzén ${ }^{\mathrm{a}, \mathrm{c}}$, Knut Ekker ${ }^{\mathrm{d}}$ and Anne-Grethe T. Berg ${ }^{\mathrm{e}, \mathrm{f}}$ \\ ${ }^{a}$ Department of Health Sciences, Nord-Trøndelag University College, Steinkjer, Norway; ${ }^{b}$ Center for Care Research, Steinkjer, Norway; \\ ${ }^{c}$ Department of Health Sciences, Mid Sweden University, Sundsvall, Sweden; ${ }^{d}$ Department of Agriculture and Information Technology, \\ Nord-Trøndelag University College, Steinkjer, Norway; ${ }^{e}$ Department of Clinical Medicine, Vivarium-Haukeland sykehus, University of \\ Bergen, Bergen, Norway; ${ }^{f}$ Norway/Norwegian Food Safety Authority, Steinkjer, Norway
}

(Received 21 January 2014; accepted 19 May 2014)

\begin{abstract}
Objective: Depression constitutes a major health problem for older people, in this study defined as people 65 years of age and older. Previous studies have shown that mental health among older people who live with animals could be improved, but contrary results exist as well. Therefore, the objective of the present population study was to compare the self-rated depression symptoms of both female and male non-pet owners, cat owners, and dog owners.

Method: The participants in this cross-sectional population study included 12,093 people between the ages of 65 and 101 . One thousand and eighty three participants owned cats and 814 participants owned dogs. Self-rated depression symptoms were measured using HADS-D, the scale of self-administered depression symptoms in HADS (Hospital Anxiety and Depression Scale).

Results: The main results showed higher mean values on the HADS-D for cat owners than for both dog and non-pet owners. The latter group rated their depression symptoms the lowest. When dividing the ratings into low- and highdepression symptoms, the logistic regression analysis showed that it was more likely that males who owned cats perceived lower depression symptoms than females who owned cats. No interactions were recognized between pet ownership and subjective general health status, loneliness, or marital status.

Conclusions: Our results provide a window into the differences in health factors between older females and males who own cats and dogs in rural areas. Results from population studies like ours might increase the available knowledge base when using cats and dogs in clinical environments such as nursing homes.
\end{abstract}

Keywords: depression; quantitative methods and statistics; pet ownership; older people

\section{Introduction}

In western countries, depression constitutes a major health problem for individuals and for society in general (Alonso et al., 2004; Kessler, 2006). Depression has a strong tendency to recur in older people (Reynolds et al., 2006). Correspondingly, the results in Grav, Hellzen, Romild, and Stordal (2012a) and Stordal, Mykletun, and Dahl (2003) show age-related increases in depression. Even given the well-known gender difference concerning depression in women (Nolen-Hoeksema, 2001), the impact of age and gender on an individual's susceptibility to depression varies among different studies depending on methodological heterogeneity (Vink, Aartsen, Robert, \& Schoevers, 2008). For example, in the study by Basset and Moore (2013), depressive symptoms were present in women and not in men; but in Grav, Stordal, Romild, and Hellzen $(2012 b)$ - a population study - older men were overrepresented when comparing gender and life span.

Shin and Sok (2012) found that the older people living alone were more depressed and had lower degrees of life satisfaction than older people living with their families. Living alone is associated with loneliness (Yeh ShuChuan, \& Sing Kai, 2004), which has been found to be a common feeling in older people (O'Luanaigh \& Lawlor, 2008). Those people who feel lonely or isolated are at greater risk of depression (Choi, Ransom, \& Wyllie,
2008; O'Luanaigh \& Lawlor, 2008). Loneliness is often negatively correlated with self-rated health in older adults (Alpass \& Neville, 2003). In turn, poor self-rated health is often associated with increased instances and severity of depression (Alpass \& Neville, 2003; Wu et al., 2013).

Studies have shown that both physical and mental health among people who live with animals are better than the health of those without animals (Friedman \& Thomas, 1995). In the Enmarker, Hellzen, Ekker, and Berg's (2012) study, the cat owners reported worse general health status, whereas dog owners demonstrated several health-related characteristics to a higher positive degree than both non-pet and cat owners. Banks and Banks (2002) found that dogs can ease the perception of loneliness, and Sable (1995) established that the company of a dog reduces feelings of loneliness when someone close has died. Moreover, walking a dog allows for contact with other people (McNicholas \& Collis, 2000), and in that way, the activity may alleviate feelings of loneliness.

Gilbey, McNicholas, and Collis (2007) argued, however, that there was no evidence that pet ownership reduced loneliness. Antonacopoulos, Pychyl, and Timothy (2010) found that neither cat nor dog ownership predicts feelings of loneliness or depression for individuals living alone. Further, Müllerdorf, Granström, Sahlqvist, and

*Corresponding author. Email: ingela.enmarker@hint.no 
Tillgren (2010) found that pet owners perceived their own mental health as poorer than that of non-pet owners. Parslow, Jorm, Christensen, Rodgers, and Jacomb (2005) agreed, concluding that pets do not promote the psychological health of older people, and pet owners report more depressive symptoms than non-pet owners.

Some studies have shown that mental health among people who live with animals is better than those without animals (Friedman \& Thomas, 1995). Furthermore, studies show that pets such as dogs and cats - the two most popular companion animals today (Driscoll, Macdonald, \& O'Brien, 2009) - can promote the well-being of older people (Nimer \& Lundahl, 2007; Sable, 1995). Nevertheless, an overview of the existing studies demonstrates conflicting results. Therefore, the objective of the present population study was to compare the self-rated depression symptoms of both female and male non-pet owners, cat owners, and dog owners.

\section{Method}

\section{Sample population}

The participants in the present cross-sectional population study included 12,093 people (5532 men and 6561 women) between 65 and 101 years of age $(M=74.8$, $\mathrm{SD}=6.45)$, of whom $1083(9.0 \%)$ were cat owners and $814(6.7 \%)$ were dog owners. The Nord-Trøndelag Health Study, known as the HUNT study, is one of the world's largest health population surveys. The study gathered data during three periods in Nord-Trøndelag County, Norway. The county is mostly rural with no big cities. The study is fairly representative of Norway's overall geographic and demographic factors. Data in this present study were drawn from the HUNT-3 survey study, which was carried out between 2006 and 2008. The survey response from the general older population was above $60 \%$.

\section{Measurements}

\section{Demographic factors}

In addition to age and gender, the participants were asked about marital status (married/cohabitant or living alone).

Question about pets. There was one question about pets: 'Do you have pets at home?' (cat, dog, and other fur-bearing animal/bird). Because there were just a few fur-bearing animal/bird owners $(n=53)$, these were omitted. As the aim was to compare cat and dog owners, participants who had both cats and dogs $(n=204)$ were also excluded.

Question about loneliness and self-rated general health status. The participants were also asked about their feelings of loneliness (no, a little, to a great deal, and very much), and their perceived general health status (very good, good, poor, and very poor). The measurements of loneliness and general health status were dichotomized into yes or no, and good or poor, respectively.
Questions about self-rated depression symptoms. Selfrated depression symptoms were measured using HADS$\mathrm{D}$, the scale of self-administered depression symptoms in HADS (Hospital Anxiety and Depression Scale). This scale is common in population studies when measuring depression (Nortvedt, Riise, \& Sanne, 2006). In this HUNT study, a Norwegian version was used. It consisted of seven items each (yes or no), and it especially focused on anhedonia and loss of interest, i.e., the core depressive symptoms. The internal consistency calculated by Cronbach's alpha was $\alpha=.81$. Only those participants who answered five to seven items were included in the analysis. In accordance with Grav et al. (2012a), the scores of participants who filled in five or six items were multiplied by $7 / 5$ or $7 / 6$.

\section{Data analysis}

To find out if there were any differences between the three groups, an analysis of variance was performed on the total score of HADS-D. In that way, interactions between pet ownership and gender could be explored. Marital status, loneliness, and self-rated general health status were covariates. To get an indication of low and high depression symptoms, HADS-D is commonly cut off at a score of 8 for the compounded index (Bjelland, Dahl, Haug, \& Neckelmann, 2002), and this cut-off score has often been used in other studies (e.g., Grav et al., 2012a, 2012b; Nortvedt et al., 2006). In the logistic regression analyses, participants with ratings less than 8 were labelled low depression symptoms, and ratings equal to or above 8 were labelled high depression symptoms. The computer program SPSS for Windows (version 19.0) was used, and the $p$-value of .05 was used for all analyses.

\section{Ethical considerations}

The Norwegian Data Inspectorate and the Regional Committee for Medical Research permitted HUNT-3. All participants in HUNT-3 gave written informed consent. The Board of Research Ethics in Health Region IV of Norway also approved the present study (reference number 2009/ 813-2).

\section{Results}

Table 1 shows participant demographics. The majority of participants were non-pet owners (over 80\%). Men were $20 \%$ more likely to own a pet, and similarly, participants who were married or cohabitating were $20 \%$ more likely to own a pet. Among men living alone, just over $15 \%$ owned a pet. There was a slight difference in pet ownership in relation to loneliness: $16.5 \%$ of participants who indicated that they were lonely owned a pet compared with $18 \%$ of participants who indicated that they were not lonely. There were more participants with cats who rated their general health status as poor $(9.4 \%)$ than those who rated it as good (8.5\%). For both dog and non-pet owners, the rating of good general health status was higher than poor health status. 
Table 1. Demographic factors for non-pet owners, cat owners, and dog owners in number and percentage.

\begin{tabular}{lccc}
\hline & $\begin{array}{c}\text { Non-pet } \\
\text { owners, } \\
N(\%)\end{array}$ & $\begin{array}{c}\text { Cat } \\
\text { owners, } \\
N(\%)\end{array}$ & $\begin{array}{c}\text { Dog } \\
\text { owners, } \\
N(\%)\end{array}$ \\
Demographics & & & \\
Gender & $5639(86.0)$ & $547(8.3)$ & $375(5.7)$ \\
$\quad$ Women & $4557(82.4)$ & $536(9.7)$ & $439(7.9)$ \\
$\quad$ Men & & & \\
Marital status & $5764(80.3)$ & $788(11.0)$ & $624(8.7)$ \\
$\quad$ Married/cohabitant & $2840(87.8)$ & $238(7.3)$ & $158(4.9)$ \\
$\quad$ Living alone & & & \\
Married/cohabitant & $2615(81.6)$ & $333(10.4)$ & $256(8.0)$ \\
$\quad$ Women & $3149(79.3)$ & $455(11.4)$ & $368(9.3)$ \\
$\quad$ Men & & & \\
Living alone & $2148(88.9)$ & $169(7.0)$ & $98(4.1)$ \\
$\quad$ Women & $692(84.3)$ & $69(8.4)$ & $60(7.3)$ \\
$\quad$ Men & & & \\
Loneliness & & & \\
$\quad$ No & & & \\
$\quad$ Yes & $5784(82.0)$ & $721(10.2)$ & $548(7.8)$ \\
General health status & $1789(83.5)$ & $200(9.3)$ & $155(7.2)$ \\
$\quad$ Good & $5830(84.5)$ & $588(8.5)$ & $480(7.0)$ \\
$\quad$ Poor & $3823(84.3)$ & $427(9.4)$ & $286(6.3)$ \\
\hline
\end{tabular}

Note: Internal drop-outs: Marital status $(n=681)$ and General health status $(n=659)$

\section{Differences between female and male non-pet owners, cat owners, and dog owners on self-rated HADS-D}

In the first analysis, the mean of the total score of HADSD was compared between female and male non-pet owners, cat owners, and dog owners. There was a significant difference between pet ownership and HADS-D $(F(2$, $11,607)=59.154, p<.001)$. The follow-up $t$-tests revealed significant differences between non-pet owners $(M=2.98, \mathrm{SD}=3.28)$ and cat owners $(M=4.00, \mathrm{SD}=$ $3.08)(t(11,357)=-9.804, p<.001)$, as well as between participants who had $\operatorname{dogs}(M=3.71, \mathrm{SD}=3.06)$ $(t(11,088)=-6.137, p<.001)$. There was also a significant difference between those who owned cats and those who owned dogs $(t(1895)=2.050, p=.041)$. That is, the mean of HADS-D for cat owners was higher than that for all others.

Concerning gender, there was a significant difference as well $(F(1,11,607)=5.871, p=.05)$. That is, men rated their depression symptoms to a higher degree than women. However, there was no interaction between pet ownership and gender. After adjustment with the covariates of marital status, loneliness, and self-rated general health status, the significant difference between pet ownership and HADS-D decreased but still remained $(F(2$, $8469)=3.587, p=.028)$. For gender, the significant difference increased $(F(1,8469)=26.296, p<.000)$. See Table 2 for a description of the mean and standard deviations of HADS-D.

In Table 3, the frequencies and percentages of low and high self-rated depression symptoms among pet ownership and gender are given. For cat owners, the proportion
Table 2. Descriptions of mean and standard deviation on selfrated HADS-D for demographics of non-pet, cat, and dog owners.

\begin{tabular}{|c|c|c|c|}
\hline Demographics & $\begin{array}{l}\text { Non-pet } \\
\text { owners } \\
M \text { (SD) }\end{array}$ & $\begin{array}{c}\text { Cat } \\
\text { owners } \\
M \text { (SD) }\end{array}$ & $\begin{array}{c}\text { Dog } \\
\text { owners } \\
M \text { (SD) }\end{array}$ \\
\hline \multicolumn{4}{|l|}{ Gender } \\
\hline Women & $3.88(2.94)$ & $4.30(2.94)$ & $3.78(2.85)$ \\
\hline Men & $4.15(2.97)$ & $4.33(2.90)$ & $4.23(2.98)$ \\
\hline \multicolumn{4}{|l|}{ Marital status } \\
\hline Married & $3.87(2.82)$ & $4.30(2.90)$ & $4.00(2.97)$ \\
\hline Living alone & $4.24(3.18)$ & $4.35(2.90)$ & $4.15(2.87)$ \\
\hline \multicolumn{4}{|l|}{ Loneliness } \\
\hline No & $3.48(2.66)$ & $3.97(2.78)$ & $3.65(2.77)$ \\
\hline Yes & $5.40(3.32)$ & $5.31(3.06)$ & $5.36(3.07)$ \\
\hline \multicolumn{4}{|c|}{ General health status } \\
\hline Good & $2.73(2.84)$ & $3.57(2.64)$ & $3.36(2.80)$ \\
\hline Poor & $3.89(3.63)$ & $5.10(3.09)$ & $4.80(3.07)$ \\
\hline
\end{tabular}

of women with ratings of high depression symptoms was greater than that for low ratings $(10.9 \%$ vs. $9.1 \%)$. For non-pet owners, the proportion of men with ratings of high depression symptoms was greater than low ratings (81.3\% vs. $79.4 \%)$.

\section{Predictions of pet ownership, gender, and marital status on self-rated depression symptoms}

To examine if self-rated depression symptoms could be predicted by pet ownership, gender, and marital status, a logistic regression analysis was conducted in two logistic regression models, wherein the dependent variable was low (compounded score $<8$ ) and high (compounded score $\geq 8$ ) self-rated depression symptoms.

The result in the first model showed that it was significantly more likely for cat owners to rate their depression symptoms as high than for those older participants who did not own a cat. In addition, males and solitary living conditions did predict ratings of high depressive symptoms. In the second model, including the interactions, the likelihood of cat owners rating their depression symptoms as high disappeared, but gender and marital status were still strong predictors. In contrast to female cat owners, it was more likely for men with cats to value their

Table 3. Number and percentage of low and high self-rated depression symptoms in relation to gender and pet ownership.

\begin{tabular}{llll}
\hline Gender & Pet ownership & Low $n(\%)$ & High $n(\%)$ \\
\hline Women & Non-pet owners & $4213(84.2)$ & $578(84.4)$ \\
& Cat owners & $457(9.1)$ & $75(10.9)$ \\
& Dog owners & $331(6.6)$ & $32(4.7)$ \\
Total & & $5001(100.0)$ & $685(100.0)$ \\
Men & Non-pet owners & $3316(79.4)$ & $536(81.3)$ \\
& Cat owners & $460(11.5)$ & $72(10.9)$ \\
& Dog owners & $380(9.1)$ & $51(7.7)$ \\
Total & & $4156(100.0)$ & $659(100.0)$ \\
\hline
\end{tabular}


Table 4. Result from logistic regression with low (0) and high (1) self-rated depression symptoms as dependent variable.

\begin{tabular}{|c|c|c|c|c|c|c|}
\hline \multirow[b]{2}{*}{ Included } & \multicolumn{3}{|c|}{ Model 1} & \multicolumn{3}{|c|}{ Model 2} \\
\hline & Wald & OR & $95 \% \mathrm{CI}$ & Wald & OR & $95 \% \mathrm{CI}$ \\
\hline Cat ownership (no $=0$ and yes $=1)$ & 4.927 & $1.222^{*}$ & $1.024-1.458$ & 0.984 & 1.208 & $0.831-1.756$ \\
\hline Dog ownership (no $=0$ and yes $=1$ ) & 0.022 & 0.985 & $0.801-1.210$ & 1.283 & 0.752 & $0.459-1.231$ \\
\hline Gender $($ female $=0$ and male $=1)$ & 11.052 & $1.234^{* * *}$ & $1.090-1.396$ & 16.111 & $1.326^{* * *}$ & $1.155-1.522$ \\
\hline Marital status (living alone $=0$ and cohabitant $=1$ ) & 19.202 & $0.746^{* * *}$ & $0.654-0.850$ & 24.841 & $16.111^{* * *}$ & $0.602-0.802$ \\
\hline Constant & 1098.439 & $0.157^{* * *}$ & & & & \\
\hline Cat ownership $\times$ gender & & & & 4.473 & $0.675^{*}$ & $0.469-0.972$ \\
\hline Dog ownership $\times$ gender & & & & 0.749 & 0.830 & $0.545-1.266$ \\
\hline Cat ownership $\times$ marital status & & & & 1.790 & 1.337 & $0.874-2.046$ \\
\hline Dog ownership $\times$ marital status & & & & 3.078 & 1.609 & $0.946-2.736$ \\
\hline Constant & & & & 976.919 & $0.158^{* * *}$ & \\
\hline
\end{tabular}

Note: Model 1: $R^{2}($ Nagelkerke $)=.005$, Model $\chi^{2}=27.970 ;$ Model 2: $R^{2}($ Nagelkerke $)=.007$, Model $\chi^{2}=37.202 ;{ }^{* * *} p \leq .001,{ }^{*} p \leq .05$. OR, Odds ratio; $\mathrm{CI}$, Confidence interval.

depression symptoms as low. None of the other interactions or dog ownership predicted self-rated depression symptoms among the older participants (see Table 4).

\section{Predictions of pet ownership, loneliness, and general health status on self-rated depression symptoms}

In this logistic regression model, pet ownership, loneliness, and general health status were tested as predictors to selfrated depression symptoms. As can be seen in Table 5, neither cat nor dog ownership were predictors among the older participants, but it was more likely for the lonely participants and those who evaluated their general health status as poor to rate high on depression symptoms. In the second model, these results persisted, but neither of the interactive variables significantly predicted self-rated depression symptoms.

\section{Discussion}

The results of this population study showed higher mean value in HADS-D for older female and male owners of cats than for both dog owners and non-pet owners of both genders. Compared to non-pet owners, there was also a significantly higher incidence of self-rated depression symptoms in those older participants with dogs. Besides the differences in pet ownership, there was a significant difference in gender. That is, men rated their depression symptoms to a higher degree than women, but there was no interaction between pet ownership and gender. Moreover, when examining likelihoods, cat ownership did predict high self-rated depression symptoms, and there was an interaction between gender and pet ownership. That is, it was more likely that men who had a cat rated low depressive symptoms. However, our results showed that self-identifying as lonely and self-identifying general health status as poor are stronger predictors of self-rated depressive symptoms than cat ownership. The same held true for gender and marital status, i.e., males and solitary living conditions each predicted ratings of high depression symptoms.

The mental health benefits of pet companionship compared to non-pet ownership is well documented, but there are contrary results as well. The results of the Connell, Janevic, Solway, and McLaughlin's (2007) study showed that cat owners rated their symptoms of depression to a higher degree than both dog and non-pet owners. There was also a significant difference between dog and non-pet

Table 5. Result from logistic regression with low (0) and high (1) self-rated depression symptoms as dependent variable.

\begin{tabular}{|c|c|c|c|c|c|c|}
\hline \multirow[b]{2}{*}{ Included } & \multicolumn{3}{|c|}{ Model 1} & \multicolumn{3}{|c|}{ Model 2} \\
\hline & Wald & OR & $95 \% \mathrm{CI}$ & Wald & OR & $95 \% \mathrm{CI}$ \\
\hline Cat ownership $($ no $=0$ and yes $=1)$ & 0.993 & 1.111 & $0.904-1.365$ & 0.040 & 1.037 & $0.726-1.481$ \\
\hline Dog ownership (no $=0$ and yes $=1$ ) & 0.123 & 0.959 & $0.759-1.211$ & 1.126 & 1.217 & $0.847-1.749$ \\
\hline Loneliness $($ no $=0$ and yes $=1)$ & 221.471 & $3.398^{* * *}$ & $2.893-3.992$ & 199.305 & $3.539^{* * *}$ & $2.970-4.218$ \\
\hline General health status $(\operatorname{good}=0$ and poor $=1)$ & 198.632 & $2.697^{* * *}$ & $2.350-3.096$ & 163.781 & $2.710^{* * *}$ & $2.326-3.157$ \\
\hline Constant & 1074.107 & $0.042^{* * *}$ & & & & \\
\hline Cat ownership $\times$ loneliness & & & & 0.830 & 0.817 & $0.530-1.261$ \\
\hline Dog ownership $\times$ loneliness & & & & 0.308 & 0.873 & $0.539-1.412$ \\
\hline Cat ownership $\times$ general health status & & & & 1.123 & 1.260 & $0.822-1.933$ \\
\hline Dog ownership $\times$ general health status & & & & 1.901 & 0.720 & $0.451-1.149$ \\
\hline Constant & & & & 1014.343 & $0.041^{* * *}$ & \\
\hline
\end{tabular}

Note: Adjusted for Gender and Marital status. Model 1: $R^{2}($ Nagelkerke $)=.112$, Model $\chi^{2}=510.436 ;$ Model 2: $R^{2}($ Nagelkerke $)=.113$, Model $\chi^{2}=$ $514.526 ;{ }^{* * *} p \leq .001$

OR, Odds ratio; CI, Confidence interval. 
owners to the latter group's advantage. Consistent with those researchers who conclude that pets do not promote older people's mental health, our results also showed that those without pets perceived fewer depressive symptoms.

Baun and McCabe (2003) assumed that caring for a pet might be increasingly difficult for older adults depending on personal circumstances and resources. In general, dogs are more dependent on their owners than cats, which are easier to cope with. The first model in the logistic regression analysis showed that participants who rated their depression symptoms as high were more likely to own a cat than a dog. Further, coherent with Grav et al. (2012b), our study also found gender as a significant predictor, showing that the older men rated their depression symptoms as high. In the second model, an interaction between gender and cat ownership was found, i.e., the male cat owners, in contrast to women, were more likely to rate their depression symptoms as low. Thus, in regard to depression symptoms, having a cat is more advantageous for men than for women. According to Herzog (2011), people who are more attached to their companion animals are more depressed than people who are not as close to their pets. Most research studies have shown that men and women are quite similarly attached to their domestic cats and dogs; however, Wedl et al. (2011) found that women's relationships with their cats are more intense than men's relationships with cats. This may explain our result.

Overall, older people tend to have more depression symptoms than younger people whether they own a cat, a dog, or no pet at all. This could be due to the aging process (Xue, 2011) or increased suffering from comorbid symptoms and diseases (Scott et al., 2008). Our result on self-rated general health could depend on comorbid symptoms and diseases. Another health consequence common in older people is loneliness (Alpass \& Neville, 2003). Getting older includes higher risks of losing a spouse, friends, and close family members, which may lead to increased loneliness (Dykstra, 2009; Hawkley \& Cacioppo, 2010). Fukunaga et al. (2012) showed that living alone in rural areas was significantly related to depression in older people, and O'Luanaigh and Lawlor (2008) found that those who feel lonely are at greater risk of depression. This concurs with our findings in which both loneliness and marital status influenced the rates of depression symptoms.

\section{Methodological considerations}

The measurement of depression in this study was the individual's self-rating, and perhaps this is the best indication of depression. However, the sample in this study probably does not catch the most severe cases of depression. Participation in this kind of scientific study requires the ability to answer a lot of questions and to undergo other tests. When individuals are depressed, they become introverted and may not be sufficiently socialized to meet the needs of the study. Such severe depression may also involve comorbidity factors.
When comparing older people in rural and urban areas, Bergdahl, Allard, Lundman, and Gustafson (2007) found that rural residents were significantly more depressed than urban residents. The present population study did not include big cities, so unfortunately it was not possible to test this statement. Moreover, this was a cross-sectional study from the years of 2006-2008. Considering that cats are supposed to become more common as pets in European countries, while the prevalence of dog ownership is more stable (Zentek, 2004), it would be relevant to use more up-to-date data to test if this is true for the older female and male owners of cats and dogs in rural areas too. It would also be interesting to conduct a longitudinal study and examine if depression and pet ownership among older people has changed over time. In addition, a longitudinal study would be helpful in establishing causality.

\section{Conclusion}

Pet ownership is often described without any consideration of the pet species. Therefore, in the present study, the purpose was to illuminate cat and dog ownership using non-pet ownership as a control. The overall finding shows that the prevalence of self-rated depression symptoms in older women and men do not decrease by owning a cat or a dog compared to those without pets. The results provide yet another piece of the puzzle concerning the differences between health factors, but further population studies would ideally bring more definite answers. Nevertheless, this study showed that women and men, as well as the type of pet, must be studied separately. In that way, the beneficial effect of the pet could be best tailored by choice of the animal's species and behaviour according to the older person's needs.

\section{Funding}

This study was supported by the Nord-Trøndelag Health Study (The HUNT Study), which runs by HUNT Research Centre (Faculty of Medicine, Norwegian University of Science and Technology NTNU), the Nord-Trøndelag County Council, the Central Norway Health Authority, and the Norwegian Institute of Public Health. Grants were given by Nord-Trøndelag University College, Norway.

\section{References}

Alonso, J., Angermeyer, M.C., Bernert, S., Bruffaerts, R., Brugha, T.S., Bryson, H., \& Vollebergh, W.A. (2004). Prevalence of mental disorders in Europe: Results from the European Study of the Epidemiology of Mental Disorders (ESEMeD) project. Acta Psychiatrica Scandinavica Supplement, 420, 21-7.

Alpass, F.M., \& Neville, S. (2003). Loneliness, health and depression in older males. Aging and Mental Health, 7(3), $212-216$.

Antonacopoulos, D., Pychyl, N.M., \& Timothy, A. (2010). An examination of the potential role of pet ownership, human social support and pet attachment in the psychological health of individuals living alone. Anthrozoos, 23(1), 37-54.

Banks, M.R., \& Banks, W.A. (2002). The effects of animalassisted therapy on loneliness in an elderly population. The Journals of Gerontology, 57(7), 428-432. 
Basset, E., \& Moore, S. (2013). Gender differences in the social pathways linking neighborhood disadvantage to depressive symptoms in adults. PLOS ONE, 8(10), 1-8. doi:10.1371/ journal.pone.0076554. PMCID: PMC3798396.

Baun, M.M., \& McCabe, B.W. (2003). Companion animals and persons with dementia of the Alzheimer's type: Therapeutic possibilities. American Behavioral Scientist, 47, 42-51.

Bergdahl, E., Allard, P., Lundman, B., \& Gustafson, Y. (2007). Depression in the oldest old in urban and rural municipalities. Aging \& Mental Health, 11(5), 570-578.

Bjelland, I., Dahl, A.A., Haug, T.T., \& Neckelmann, D. (2002). The validity of the hospital anxiety and depression scale: An updated literature review. Journal of Psychosomatic Research, 52(2), 69-77.

Choi, N.G., Ransom, S., \& Wyllie, R.J. (2008). Depression in older nursing home residents: The influence of nursing home environmental stressors, coping, and acceptance of group and individual therapy. Aging \& Mental Health, 12 (5), 536-547.

Connell, C.M., Janevic, M.R., Solway, E., \& McLaughlin, S.J. (2007). Are pets a source of support or added burden for married couples facing dementia? Journal of Applied Gerontology, 26(5), 472-485.

Driscoll, C.A., Macdonald, D.W., \& O’Brien, S.J. (2009). From wild animals to domestic pets, an evolutionary view of domestication. Proceedings of the National Academy of Sciences of the United States of America, 106(1), 9971-9978. doi:10.1073/pnas.0901586106

Dykstra, P.A. (2009). Older adult loneliness: Myths and realities European Journal of Ageing, 6(2), 91-100.

Enmarker, I., Hellzen, O., Ekker, K., \& Berg-Trønsdal, A.G. (2012). Health in older cat and dog owners: The HUNTstudy. Scandinavian Journal of Public Health, 40, 718-724.

Friedman, E., \& Thomas, S.A. (1995). Pet ownership, social support, and one-year survival after acute myocardial infarction in the cardiac arrhythmia suppression trial (CAST). American Journal of Cardiology, 76, 1213-1217.

Fukunaga, R., Abe, Y., Nakagawa, Y., Koyama, A., Noboru Fujise, N., \& Ikeda, M. (2012). Living alone is associated with depression among the elderly in a rural community in Japan. Psychogeriatrics, 12, 179-185.

Gilbey, A., McNicholas, J., \& Collis, G.M. (2007). A longitudinal test of the belief that companion animal ownership can help reduce loneliness. Anthrozoos, 20(4), 345-353.

Grav, S., Hellzen, O., Romild, U. \& Stordal, E. (2012a) Association between social support and depression in the general population: The HUNT study, a cross-sectional survey. Journal of Clinical Nursing, 21(1-2), 111-120.

Grav, S., Stordal, E., Romild, U.K., \& Hellzen, O. (2012b). The relationship among neuroticism, extraversion, and depression in the HUNT study: In relation to age and gender. Issues in Mental Health Nursing, 33(11), 777-785.

Hawkley, L.C., \& Cacioppo, J.T. (2010). Loneliness matters: A theoretical and empirical review of consequences and mechanisms. Annals of Behavioural Medicine, 40(2), $218-227$.

Herzog, H. (2011). The impact of pets on human health and psychological well-being: Fact, fiction, or hypothesis? Current Directions in Psychological Science, 20, 236-239.

Kessler, R.C. (2006). The epidemiology of depression among women. In C.L.M. Keyes \& S.H. Goodman (Eds.), Women and depression (pp. 22-37). New York, NY: Cambridge University Press.
McNicholas, J., \& Collis, G. (2000). Dogs as catalysts for social interactions: Robustness of the effect. British Journal of Psychology, 91(1), 61-70.

Müllersdorf, M., Granström, F., Sahlqvist, L., \& Tillgren, P. (2010). Aspects of health, physical/leisure activities, work and socio-demographics associated with pet ownership. Scandinavian Journal of Public Health, 38(1), 53-63.

Nimer, J., \& Lundahl, B. (2007). Animal-assisted therapy: A meta-analysis. Anthrozoos, 20(3), 225-238.

Nolen-Hoeksema, S. (2001). Gender differences in depression Current Directions in Psychological Science, 10, 173-176.

Nortvedt, M.W., Riise, T., \& Sanne, B. (2006). Are men more depressed than women in Norway? Validity of the hospital anxiety and depression scale. Journal of Psychosomatic Research, 60(2), 195-198.

O'Luanaigh, C., \& Lawlor, B.A. (2008). Loneliness and the health of older people. International Journal of Geriatric Psychiatry, 23, 1213-1221.

Parslow, R.A., Jorm, A.F., Christensen, H., Rodgers, B., \& Jacomb, P. (2005). Pet ownership and health in older adults: Findings from a survey of 2,551 community-based Australians aged 60-64. Gerontology, 51(1), 40-47.

Reynolds, C.F. III, Dew, M.A., Pollock, B.G., Mulsant, B.H., Frank, E., Miller, M.D., ... Kupfer, D.J. (2006). Maintenance treatment of major depression in old age. The New England Journal of Medicine, 354(11), 1130-1138.

Sable, P. (1995). Pets, attachment, and well-being across the life cycle. Social Work, 40(3), 334-341.

Scott, K.M., Von Korff, M., Alonso, J., Angermeyer, M., Bromet, E.J., Bruffaerts, R., ... Williams, D. (2008). Age patterns in the prevalence of DSM-IV depressive/anxiety disorders with and without physical co-morbidity. Psychological Medicine, 38(11), 1659-1669.

Shin, S.H., \& Sok, S.R. (2012). A comparison of the factors influencing life satisfaction between Korean older people living with family and living alone. International Nursing Review, 59, 252-258.

Stordal, E., Mykletun, A., \& Dahl, A.A. (2003). The association between age and depression in the general population: A multivariate examination. Acta Psychiatrica Scandinavica, 107(2), 132-141.

Vink, D., Aartsen, M.J., Robert, A., \& Schoevers, R.A. (2008). Risk factors for anxiety and depression in the elderly: A review. Journal of Affective Disorders, 106(1-2), 29-44.

Wedl, M., Bauer, B., Grabmayer, C., Gracey, D., Spielauer, E., Day, J., \& Kotrschal K. (2011). Factors influencing the temporal patterns of dyadic behaviours and interactions between domestic cats and their owners. Behavioural Processes, 86, $58-67$.

Wu, S., Wang, R., Zhao, Y., Ma, X., Wu, M., Yan, X., \& He, J. (2013). The relationship between self-rated health and objective health status: A population-based study. BMC Public Health, 13(1), 320. doi:10.1186/1471-2458-13-320

Xue, Q.L. (2011). The frailty syndrome: Definition and natural history. Clinics in Geriatric Medicine, 27(1), 1-15.

Yeh Shu-Chuan, J., \& Sing Kai, L. (2004). Living alone, social support, and feeling lonely among the elderly. Social Behavior and Personality: An International Journal, 32(2), $129-138$.

Zentek, J. (2004). A changing landscape: The pet food market in Europe. In: T.P. Lyons \& K.A. Jacques (Eds.), Nutritional Biotechnology in the Feed and Food Industries (pp. 517-521). Nottingham: University Press. 